\title{
Chest pain in women: a study of prevalence and mortality follow up in South Wales
}

\author{
M J CAMPBELL, ${ }^{1}$ P C ELWOOD, ${ }^{2} \mathrm{~S} \mathrm{ABBAS},^{3}$ AND W E WATERS \\ From Community Medicine, 1 Southampton General Hospital, Southampton SO9 4XY, MRC Epidemiology \\ Unit (S Wales), ${ }^{2}$ Cardiff, UK, and University Mains, ${ }^{3}$ Malaysia
}

SUMMARY The London School of Hygiene cardiovascular questionnaire was administered by. interviewers in a community survey of 1428 women aged 45-74 living in the Rhondda Fach in south Wales. The results were analysed after a 12 year follow up for mortality. The prevalence of angina was similar to that of a Swiss population, where the method of administration of the questionnaire was similar. The risk of dying associated with angina was some $50 \%$ higher than that for women without angina, significant at the 5\% level. The risk was greatest for women aged 45-54 when angina accounted for some 15\% of deaths in the follow up period. Grade 2 angina was associated with a higher mortality from coronary heart disease, with more than double the risk. The overall risk of dying associated with angina did not appear to decline with time.

The London School of Hygiene cardiovascular questionnaire ${ }^{2}$ has been widely used as a screening device for angina pectoris and myocardial infarction. ${ }^{3-11}$ It has been mainly used to study male populations, although several studies have also included women. ${ }^{4-11}$ The purpose of this paper is to report the prevalence of angina in a community survey of women living in the Rhondda Fach in south Wales and to examine the mortality in relation to angina in a 12 year follow up study, allowing for age and smoking effects.

\section{Methods}

All women aged between 20 and 74 living in a defined area of the Rhondda valley in south Wales in 1967 were invited to attend a survey that was mainly haematological. The response rate was over $86 \%$. The over 65 age group were not studied in part of the valley. A number of trained observers administered a version of the London School of Hygiene cardiovascular questionnaire. ${ }^{2}$ The results of the cross sectional study, in relation to sucrose consumption, have been reported previously. ${ }^{7}$ The women were followed up in 1979 by home visiting. Survival was assumed only if the subject, or a close relative, was interviewed or if a letter was recieved from the subject. For every death up to the end of 1978 a certified copy of the death certificate was inspected and the cause classified by the
International Classification of Diseases (8th revision). Follow up was $99.9 \%$.

Mortality was low for younger women and so we only present the results of the women over 45 . Statistical methods have been described by Campbell, ${ }^{12}$ and were implemented in the programming language Genstat. ${ }^{13}$ To express the excess mortality associated with angina we used the population attributable proportion ${ }^{14}$ - that is, an estimate of the proportion of subjects dying in the population attributable to angina. This is given by:

$1-$ Prob $\{$ dying in follow up $\mid$ angina free $\} / P\{$ dying in follow up\}.

To assess the effect of angina allowing for various confounding effects, together with significance levels, we used a generalised linear modelling approach. Given that $\mathbf{P}$ is the probability of surviving the follow up period, we modelled the logistic transformation of $\mathrm{P}, \log (\mathrm{P} / 1-\mathrm{P})$ and also the complentary $\log -\log$ of $\mathrm{P}, \log \{-\log (1-\mathrm{P})\}$, as suggested by Woodbury et $a^{15}$ for longitudinal studies. The results were similar for either transformation. The regression coefficient associated with angina, when exponentiated, is termed the odds ratio, and closely approximates the relative risk. ${ }^{16}$

Grade 1 angina is defined as pain in the chest that occurs when walking uphill or hurrying which forces the subject to slow down or stop, and which is relieved after 10 minutes' rest. Grade 2 angina is 
defined as the pain occuring also when the subject is walking at an even pace on the level. Questions regarding possible infarction-that is, a severe pain across the front of the chest lasting for half an hour or more-were omitted. Since angina is precluded if the chest pain lasts more than 10 minutes, we defined a further classification, consisting of people who get a chest pain provoked by walking at an even pace on the level, which continues for longer than 10 minutes when the subject is resting.

\section{Results}

Table 1 shows the prevalence of angina by age group. These figures are somewhat higher than equivalent figures for men, ${ }^{3-5} 8$ but several studies have shown that the prevalence of angina is higher in women than in men. ${ }^{8} 1011$

Table 1 Prevalence (\%) of angina in women aged 45-74

\begin{tabular}{|c|c|c|c|c|c|c|}
\hline Age & No angina & Grade 1 & Grade 2 & $\begin{array}{l}\text { Chest pain } \\
>10 \text { mins }\end{array}$ & $\begin{array}{l}\text { Total } \\
\text { No }\end{array}$ & $\begin{array}{l}\text { No } \\
\text { unclassified }\end{array}$ \\
\hline $\begin{array}{l}45-49 \\
50-54 \\
55-59 \\
60-64 \\
65-69 \\
70 \cdot 74\end{array}$ & $\begin{array}{l}83 \cdot 7 \\
83 \cdot 8 \\
75 \cdot 3 \\
77 \cdot 3 \\
73 \cdot 9 \\
87 \cdot 1\end{array}$ & $\begin{array}{r}10 \cdot 4 \\
10 \cdot 1 \\
14 \cdot 1 \\
14 \cdot 9 \\
15 \cdot 2 \\
9.7\end{array}$ & $\begin{array}{l}3 \cdot 5 \\
4 \cdot 2 \\
8 \cdot 2 \\
6 \cdot 4 \\
8 \cdot 7 \\
3 \cdot 2\end{array}$ & $\begin{array}{r}2 \cdot 4 \\
2 \cdot 0 \\
2 \cdot 4 \\
1 \cdot 4 \\
2 \cdot 2 \\
-\end{array}$ & $\begin{array}{r}375 \\
357 \\
291 \\
282 \\
92 \\
31\end{array}$ & $\begin{array}{l}3 \\
1 \\
3 \\
2 \\
1 \\
0\end{array}$ \\
\hline $\begin{array}{l}45-74 \\
\text { No }\end{array}$ & $\begin{array}{l}80 \cdot 2 \\
1146\end{array}$ & $\begin{array}{c}12 \cdot 3 \\
175\end{array}$ & $\begin{array}{c}5 \cdot 5 \\
79\end{array}$ & $\begin{array}{r}2 \cdot 0 \\
28\end{array}$ & 1428 & 10 \\
\hline
\end{tabular}

Table 2 shows the percentage dead in the follow up period, by age and angina status. The overall mortality for the group with chest pain lasting more than 10 minutes is not very different from that of the "no angina" group, and for all subsequent analyses the two have been pooled. Overall, it appears that mortality is higher for subjects with grade 1 and grade 2 angina but that this excess is mainly confined to women aged 45-54. The high mortality for women over 65 with grade 2 angina is based on six deaths out of nine subjects. A total of $57 \%$ of the deaths in the

Table 2 Percentage dead in 12 year follow up: angina group. Figures in parentheses are deaths from coronary heart disease (ICD 410-414, 8th revision)

\begin{tabular}{lccll}
\hline Age group & No angina & Grade 1 & Grade 2 & $\begin{array}{l}\text { Chest pain } \\
>10 \text { mins }\end{array}$ \\
\hline $45-54$ & 9 & 20 & 18 & 0 \\
$55-64$ & 18 & 22 & 24 & 27 \\
$65-74$ & 35 & 24 & 67 & 50 \\
$45-74$ & $14.5(3.8)$ & $21 \cdot 1(4 \cdot 0)$ & $26.6(8.9)$ & $13.8(0)$ \\
No & $166(43)$ & $37(7)$ & $21(7)$ & $4(0)$ \\
\hline
\end{tabular}

grade 2 group were due to any heart disease (ICD $393-429$ ) compared with $33 \%$ in both the grade 1 and the no angina group. The death rate over time for the angina and no angina groups is plotted in the figure. As would be expected, this shows an increasing hazard for the women with no angina, since they were basically a healthy population to start with. It shows that the angina group have a consistently higher hazard, even 10 years after the survey, although because of the low numbers the hazard plot fluctuates considerably. Table 3 shows the proportion of deaths attributable to angina by age group. It can be seen that over the 12 year follow up angina grades 1 and 2 can be associated with about $15 \%$ of deaths in the 45-54 year age group, but that this proportion declines with age. Again the increased rate for angina grade 2 in the 65 and over age group is based on only nine subjects.

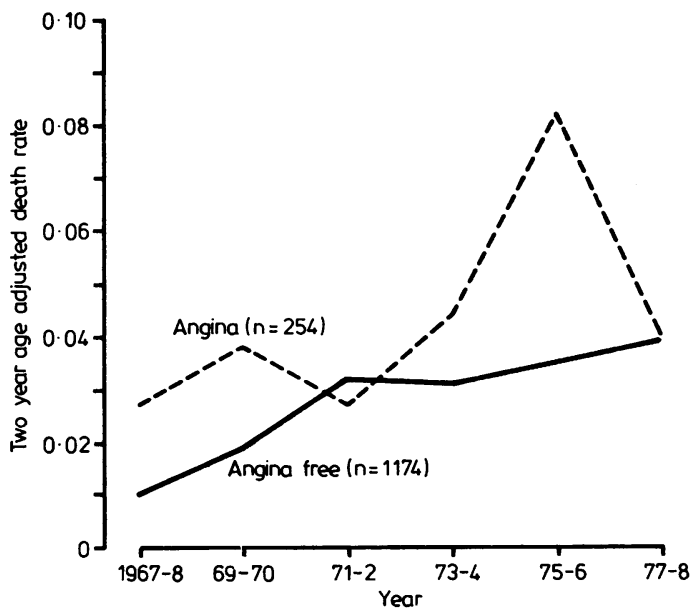

Two year death rate by angina grouping.

Smoking is usually a major confounding factor in epidemiological studies but in table 4 we fail to show any relation between smoking and angina. The table shows that the proportion of smokers drops in the older women but there is no consistent relationship with an angina group. Since smoking is an important determinant of subsequent mortality, however, it was retained in the modelling process.

Table 3 Percentage dying attributable to angina*

\begin{tabular}{lcc}
\hline Age & Angina $1+2$ & Angina 2 alone \\
\hline $45-54$ & $14 \cdot 9$ & $2 \cdot 9$ \\
$55-64$ & $4 \cdot 7$ & $2 \cdot 1$ \\
$65-74$ & $2 \cdot 2$ & $7 \cdot 0$ \\
\hline
\end{tabular}

* $100 \times(1-$ prob $\{$ dying $/$ angina free $\}$ /prob $\{$ dying in follow up\}). 
Table 4 Percentage smokers by angina groups

\begin{tabular}{llll}
\hline & & \multicolumn{2}{l}{ Angina group } \\
\cline { 3 - 4 } Age & No angina & Grade 1 & Grade 2 \\
\hline $45-54$ & 48 & 53 & 50 \\
$55-64$ & 31 & 22 & 24 \\
$65-74$ & 8 & 6 & 22 \\
\hline
\end{tabular}

$\left(x_{6}^{2}=4 \cdot 26, p>0 \cdot 2\right)$.

Age was originally classified into six groups of five years each and smoking into never smoked, less than four, 4-15, more than 15 cigarettes a day, and exsmoker. With such a large number of levels of a factor, however, the power to detect interactions is poor, especially since the number of subjects in some of the subgroups is low. To examine the possibility of pooling we performed a multiple logistic regression, with the probability of surviving the follow up as the dependant variable, and with age, smoking, and angina groups as the independent variables. By comparing the coefficients of the regression equation we decided to pool the heavy and medium smoking groups, and also the never smoked and ex-smoker groups. The grade 1 and grade 2 angina groups were not pooled, but the small group with chest pain of more than 10 minutes was combined with the no angina group.

We constructed models based on age, smoking, and angina status to predict the probability of dying or the probability of dying from coronary heart disease in the follow up period. Including smoking in the model did not materially affect the coefficients associated with angina, but reduced the standard errors of the coefficients. We were also able to replace the grouped age factor by the continuous variable age without altering the other coefficients to any degree. The main effects of each factor emerged as significant, at least at the $5 \%$ level. For total deaths there was also a significant second order interaction between age and angina. We divided the follow up period into two roughly equal sections. The analysis was conducted, firstly, on subjects who died before 31 December 1972, compared with the survivors, and then on subjects who died between 31 December 1972 and 31 December 1978 compared with those who survived beyond 1978. Table 5 shows the odds ratios, derived from the regression equations. These show that, overall, grade 2 angina carries a slightly higher odds ratio than grade 1 , although the difference is not significant. Only the grade 2 angina has an odds ratio significantly different from 1 . The pooled odds ratio was 1.52 , significantly greater than 1 at the $1 \%$ level. Comparing the two follow up periods, we see that the coefficients are similar, implying that the risk does not appear to be changing with time.
Table 5 shows the odds ratio of coronary heart disease for the two grades of angina. The odds ratio for grade 1 angina is close to unity. The risk associated with Grade 2 angina, however, has increased. It would appear that the risk is greater in the early part of the follow up, but the numbers are too small for any real interpretation.

Since the analysis showed a significant age-angina interaction, we analysed the total number of deaths by three 10 year age groups, and the results are displayed in table 6 . For grade 1 angina the risk is clearly greatest for the 45-54 age group, with the risk declining with age. The risk to the 65-74 age group is actually less than unity, although the confidence interval includes it. Splitting by age reduces the number in the grade 2 group to such an extent that none of the risk values are significantly greater than 1. Because of the low numbers we have not exmained the deaths from coronary heart disease by age group.

Table 5 Risk relative to the angina free group, allowing for age and smoking

\begin{tabular}{|c|c|c|c|c|}
\hline & & $1967-72$ & $1973-78$ & $1967-78$ \\
\hline \multicolumn{5}{|c|}{ Dependent variable: death in follow up } \\
\hline $\begin{array}{l}\text { Angina grade } 1 \\
\text { Angina grade } 2\end{array}$ & $\begin{array}{l}\text { OR } \\
95 \% \text { CI } \\
\text { OR } \\
95 \% \text { CI }\end{array}$ & $\begin{array}{c}1 \cdot 44 \\
0.80-2 \cdot 60 \\
1 \cdot 67 \\
0.77-3 \cdot 65\end{array}$ & $\begin{array}{c}1 \cdot 38 \\
0 \cdot 87-2 \cdot 20 \\
2 \cdot 01 \\
1 \cdot 12-3 \cdot 61\end{array}$ & $\begin{array}{c}1.39 \\
0.97-1.98 \\
1 \cdot 82 \\
1 \cdot 16-2 \cdot 85\end{array}$ \\
\hline \multicolumn{5}{|c|}{ Dependent variable: death from coronary heart disease } \\
\hline $\begin{array}{l}\text { Angina grade } 1 \\
\text { Angina grade } 2\end{array}$ & $\begin{array}{l}\text { OR } \\
95 \% \text { CI } \\
\text { OR } \\
95 \% \text { CI }\end{array}$ & $\begin{array}{c}0.94 \\
0.21-4.17 \\
3.07 \\
0.85-11.07\end{array}$ & $\begin{array}{c}1 \cdot 16 \\
0.44-3 \cdot 05 \\
2 \cdot 29 \\
0.76-6.84\end{array}$ & $\begin{array}{c}1.07 \\
0.47-2.45 \\
2.35 \\
1.00-5 \cdot 53\end{array}$ \\
\hline
\end{tabular}

$\mathrm{OR}=$ Odds ratio.

$\mathrm{CI}=$ Confidence interval.

Table 6 Risk relative to angina free group

\begin{tabular}{llccc}
\hline \multicolumn{5}{c}{ Age differences } \\
& \multicolumn{5}{c}{ Dependent variable: death in follow up 1967-78 } \\
& \multicolumn{5}{c}{ Age 45-54 } & $55-64$ & $65-74$ \\
\hline Angina grade 1 & OR & 2.39 & 1.26 & 0.63 \\
& $95 \%$ CI & $1.35-4.21$ & $0.67-5.55$ & $0.28-1.37$ \\
Angina grade 2 & OR & 2.15 & 1.40 & 2.56 \\
& $95 \%$ CI & $0.86-5.37$ & $0.53-3.74$ & $0.87-7.52$ \\
\hline
\end{tabular}

\section{Discussion}

Rose et al have shown that the method of administration of an angina questionnaire can affect the estimates of prevalence. ${ }^{4}$ The prevalence figures agree quite well with those of Tibbling ${ }^{10}$ of $13 \cdot 4 \%$ for women aged 55, grades $1+2$ in Sweden, and those of 
Gutzwiller $e^{a} a^{6}$ of $11.0 \%$ and $4.9 \%$ grades 1 and 2 respectively for women aged 50-69 in Switzerland. The Swedish study was conducted by post, whereas the Swiss one was by interviewer in a similar manner to the present study. Male population studies ${ }^{4}{ }^{5}$ might lead one to suppose that only our grade 2 angina is the correct definition. Our study also shows that the requirement that the pain should usually go away within 10 minutes is relevant to subsequent mortality. The overall odds ratios of 1.4 and 1.8 for grade 1 and grade 2 respectively compare well with the figure of 1.64 for non-migrant British women given by Feinlieb et al." The question "Do you get chest pain when walking at an even pace on the level" would appear to be more specific to heart disease, which was also noted by Zeiner-Henrikson, ${ }^{9}$ for which a higher relative risk is associated. This relative risk would appear to be greatest in the years immediately following the questionnaire. Nevertheless, angina appears to carry a high relative risk of death even six years subsequently.

For women over 45 relative risk is greater in women aged $45-54$. The study did not have sufficient numbers of older women to examine whether only grade 2 angina is a serious risk factor in women over 65. The Norwegian study ${ }^{9}$ showed that the risk for grade 2 declined over the age of 65 , but that for grade 1 did not. They did, however, report a decline in the risk for the male population.

Thus we have shown that in a Welsh, non-migrant community angina identified by questionnaire is associated with a higher cardiovascular mortality and higher overall mortality, particularly in the 45-54 age group.

We are grateful to Mr Fred Moore and Mrs J Hughes for obtaining the causes of death, Mr P Sweetnam for helpful discussions, and Miss J Dicks for typing the manuscript.

\section{References}

${ }^{1}$ Rose GA. The diagnosis of ischaemic heart pain and intermittent claudication in field surveys. Bull WHO 1962; 27: 645-50.

${ }^{2}$ Rose GA, Blackburn H. Cardiovascular survey methods. (Monograph series No 56. 1-188). Geneva: World Health Organisation, 1968.

${ }^{3}$ Rose G. Predicting coronary heart disease from minor symptoms and electrocardiographic findings. $\mathrm{Br} \mathrm{J} \mathrm{Prev}$ Soc Med 1971; 25: 94-6.

${ }^{4}$ Rose GA, McCartney P, Reid DD. Self-administration of a questionnaire on chest-pain and intermittent claudication. Br J Prev Soc Med 1977; 31: 42-8.

${ }^{5}$ Blackwelder WC, Kagan A, Gordon T, Rhoads GG. Comparison of methods for diagnosing angina pectoris: the Honolulu heart study. Int J Epidemiol 1981; 10: 211-5.

${ }^{6}$ Gutzwiller F, Junod B, Epstein FH, et al. The National Research program 1A: prevalence of chest pain in four Swiss cities. Soz Praventivmed 1980; 25: 275-9. (In German.)

${ }^{7}$ Elwood PC, Waters WE, Moore S, Sweetnam P. Sucrose consumption and ischaemic heart disease in the community. Lancet 1970; i: 1014-6.

${ }^{8}$ Zeiner-Henriksen T. Cardiovascular disease symptoms in Norway-a study of prevalence and mortality follow up. J Chron Dis 1971; 24: 553-67. Zeiner-Henriksen T. Six year mortality related to
cardiorespiratory symptoms and environmental risk factors in a sample of the Norwegian population. $J$ Chron Dis 1976; 29: 15-33.

${ }^{10}$ Tibbling L. Oesophageal dysfunction and angina pectoris in a Swedish population selected at random. Acta Med Scand (suppl) 1981; 644: 71-4.

${ }^{11}$ Feinleib M, Lambert PM, Zeiner-Henriksen T, Rogot E Hunt BM, Ingster-Moore L. The British-Norwegian migrant study -analysis of parameters of mortality differentials associated with angina. Biometrics (suppl) 1982; 38: 55-74.

${ }^{12}$ Campbell MJ. The analysis using Genstat of anaemia, sugar intake and Quetelet's Index as prognostic indicators in women. Statistics in Medicine 1983; 2: 223-8.

${ }^{13}$ Alvey NG, Banfield CF, Baxter RI, et al. GENSTAT A general statistical program. Harpenden Statistics Department, Rothamsted Experimental Station, 1980.

14 Waltner-Toems D. Nomenclature of risk assessment in $2 \mathrm{x}$ 2 tables. Int J Epidemiol 1982; 11: 411-3.

${ }^{15}$ Woodbury MA, Manton KG, Stallard E. Longitudinal models for chronic disease risk: an evaluation of logistic multiple regression and alternatives. Int $J$ Epidemiol 1981; 10: 187-97.

${ }^{16}$ Fleiss JL. Statistical methods for ratio and proportions. 2nd ed. New York: John Wiley, 1981: 64-75. 